\title{
Immunohistochemical characterization of the anti-Müllerian hormone receptor type 2 (AMHR-2) in human testes
}

\author{
A. Sansone $\mathbb{1}^{1,2} \cdot$ A. M. Isidori $\mathbb{(}^{2} \cdot$ S. Kliesch $\mathbb{1}^{1} \cdot$ S. Schlatt $\mathbb{( I D}^{1}$
}

Received: 21 November 2019 / Accepted: 17 January 2020 / Published online: 6 February 2020

(c) The Author(s) 2020

\begin{abstract}
Purpose In males, AMH is secreted by immature Sertoli cells; following exposure to endogenous androgens, Sertoli cells undergo a process of maturation which ultimately inhibits AMH expression to undetectable levels in the serum. However, expression of AMH receptor (AMHR-2) has never been studied in human testes, and high intratubular concentrations of AMH have been reported in recent literature. We therefore assessed expression of AMHR-2 in several testicular tissue samples by immunohistochemistry (IHC).

Methods The IHC method was first validated on tissue samples from healthy human testis $(n=2)$ and from marmoset ovary $(n=1)$. The same method was then used for assessment on testicular histopathology specimens from patients with mixed atrophy (MA, $n=2)$, spermatogenetic arrest ( $\mathrm{SA}, n=2)$, Sertoli cell-only syndrome (SCO, $n=1)$, Klinefelter syndrome (KS, $n=1$ ), and nonseminomatous germ cell tumors (NSGCT, $n=1$ ). Tissue samples from two subjects at different pubertal stages (AndroProtect (AP), aged 5 and 14 years) with hematological malignancies were also retrieved.

Results In adult men, AMHR-2 was expressed on peritubular mesenchymal cells, with patterns closely mirroring $\alpha$-smooth muscle actin expression. Similar patterns were preserved in almost all conditions; however, in nonseminomatous germ cell tumors the tissue architecture was lost, including AMHR-2 expression. More positive and diffuse staining was observed in tissue samples from prepubertal testes.

Conclusions In specimens from both healthy and affected testes, AMHR-2 expression appears weaker in adult than in prepubertal tissue sections. The persistence of AMHR-2 expression seemingly hints at a possible effect of intratesticular AMH on the tubular walls.
\end{abstract}

Keywords Immunohistochemistry $\cdot$ AMH $\cdot$ AMHR-2 $\cdot$ Testis

\section{Introduction}

Anti-Müllerian Hormone (AMH) is a glycoprotein belonging to the TGF- $\beta$ superfamily [1], produced by granulosa cells of the preantral and small antral follicles in females and by immature Sertoli cells in males [2, 3].

In men, secretion of AMH is largely dependent on the maturity status of the Sertoli cell. In fetal life, expression of

S. Schlatt

Stefan.Schlatt@ukmuenster.de

1 Centre of Reproductive Medicine and Andrology, University Hospital of Münster, Albert-Schweitzer Campus 1, 48149 Münster, Germany

2 Department of Experimental Medicine, Food Science and Endocrinology, Sapienza University of Rome, 00161 Rome, Italy
AMH by Sertoli cells is triggered by $\mathrm{SOX} 9$, later followed by different transcription factors including FSH, SF1, and WT1. Patterns of protein expression change during the first years of life: exposure to endogenous testosterone and morphological changes in Sertoli cells have been reported, including distinct changes in histoskeleton architecture $[4,5]$.

An ever-growing body of evidence is supporting a role for AMH in the clinical setting, such as the assessment of ovarian reserve for females [6]. However, in males, AMH is mostly used in prepubertal patients: in the fetus, by binding to its receptor [7], AMH induces changes in the morphology of the Müllerian duct mesenchyme, ultimately resulting in apoptosis in the cells of paramesonephric ducts, regression of internal female genitalia, and epithelia-mesenchymal transformation [8]. Mutations in either the protein or the receptor genes impair the binding: male subjects with such alterations develop a rare condition defined persistent 
Müllerian duct syndrome (PMDS). In PMDS, remnants of the Müllerian ducts are observed in phenotypically normal males [9]. AMH dosage can also prove useful in differential diagnosis between constitutional delay of growth and congenital hypogonadotropic hypogonadism, but little uses are known so far for AMH in adult life.

AMH concentration in serum are significantly reduced after the transition to adulthood; however, significantly higher concentrations are reached in the seminiferous tubules [7], suggesting that AMH secretion might have effects on gonadal health and function even after full testicular maturation. In addition, serum AMH has been investigated as a possible biomarker of spermatogenesis and successful sperm retrieval rate in subjects with nonobstructive azoospermia: while there is limited evidence against the diagnostic value of AMH [10-12], more recent reports suggest that the AMH-to-testosterone ratio could provide useful insight for sperm retrieval techniques [13].

As expected, AMH exerts its biological functions thanks to the interaction with its receptor (AMHR), which is actually a heteromeric complex of types I and II single transmembrane serine/threonine kinase receptors. While the type 2 receptor (AMHR-2) has been identified since the early 1990s [14], the type 1 receptor has been discovered only in more recent times $[15,16]$. AMHR-2 seems to be involved in ligand binding, whereas AMHR-1 is a signal transducer shared with other members of the TGF- $\beta$ superfamily [15]. While some studies have reported different patterns of AMH expression in different testicular affections, such as testicular hypotrophy [17], varicocele [18, 19], and cryptorchidism [20], very little is known concerning how AMHR-2 expression is influenced by gonadal pathologies.

We aimed to assess patterns of AMHR-2 expression both in healthy subjects and in different testicular conditions by performing immunohistochemistry (IHC) on testicular tissue sections. We validated our method in animal models, using marmoset ovary as a positive control, before examining human tissue samples.

\section{Materials and methods}

\section{Validation protocol}

\section{Ovarian tissue}

Ovarian tissue for validation was obtained from biopsies from healthy adult marmoset (Callithrix jacchus) from the institutional breeding colony. Approval for the use of tissue for experimental purposes was provided by LANUV NRW (Az: 84-02.05.50.16014).

\section{Testicular tissue}

Ethical approval for the use of testicular tissue was obtained from the ethical committee of the Ärztekammer WestfalenLippe (no. 2012-555-f-S). Testicular tissue was obtained from testicular samples from the institutional tissue bank consisting of fixed and paraplast-embedded samples. All sections had previously been prepared by using the same protocol: testicular tissue was fixed by immersion in Bouin's fluid for $24 \mathrm{~h}$, washed in $70 \%$ alcohol, dehydrated in a graded series of ethanol, transferred into n-butylacetate as intermedium, and embedded in paraplast before being cut in $5 \mu \mathrm{m}$ sections. Sections were prepared for staining by deparaffinization and rehydration. Antigen retrieval was performed for $3 \mathrm{~min}$ in a microwave oven using citrate buffer as a medium. For validation purposes testes from two men were used who had undergone bilateral orchiectomy for androgen deprivation therapy for prostate cancer. Both samples were selected for qualitatively normal spermatogenesis (according to the Bergmann-Kliesch score [21]).

\section{Study protocol}

\section{Testicular tissue}

Human testis tissue samples with well-defined pathologies became available from the institutional tissue/data bank (Androbase) in order to assess the expression patterns of AMHR-2 in sections included tissue samples from patients with different testicular affections, including mixed atrophy (MA, $n=2$ ), spermatogenetic arrest (SA, $n=2)$, Sertoli cellonly syndrome (SCO, $n=1$ ), Klinefelter syndrome (KS, $n=$ 1 ), and nonseminomatous germ cell tumors (NSGCT, $n=1$ ). Sections of testicular tissue belonging to two subjects at different stages of puberty (AndroProtect (AP), aged 5 and 14 years) with hematological malignancies were also retrieved.

\section{Immunohistochemistry (IHC)}

The primary antibody used for this study was a monoclonal mouse antibody against AMHR-2 produced by Abcam, Cambridge, MA, USA (ab64762). According to the product datasheet, the antibody would bind to the aminoacidic sequence NANYSHLPPPGSPG, corresponding to aminoacids 117-130 of Human AMHR-2 and be valid of IHC staining following heat-mediated antigen retrieval.

\section{Staining technique}

After rehydration and washing, tissue sections were incubated in primary antibody, using different dilutions. For the validation protocol, marmoset ovarian sections were stained for AMHR-2 using three dilutions of the antibody (1:100, 
Fig. 1 Validation protocol for AMHR-2 IHC staining. Tissue sections from marmoset ovary; $\times 20$ magnification. a primary antibody omitted, using hematoxylin counterstaining only; b 1:500 AMHR-2 staining and hematoxylin counterstaining
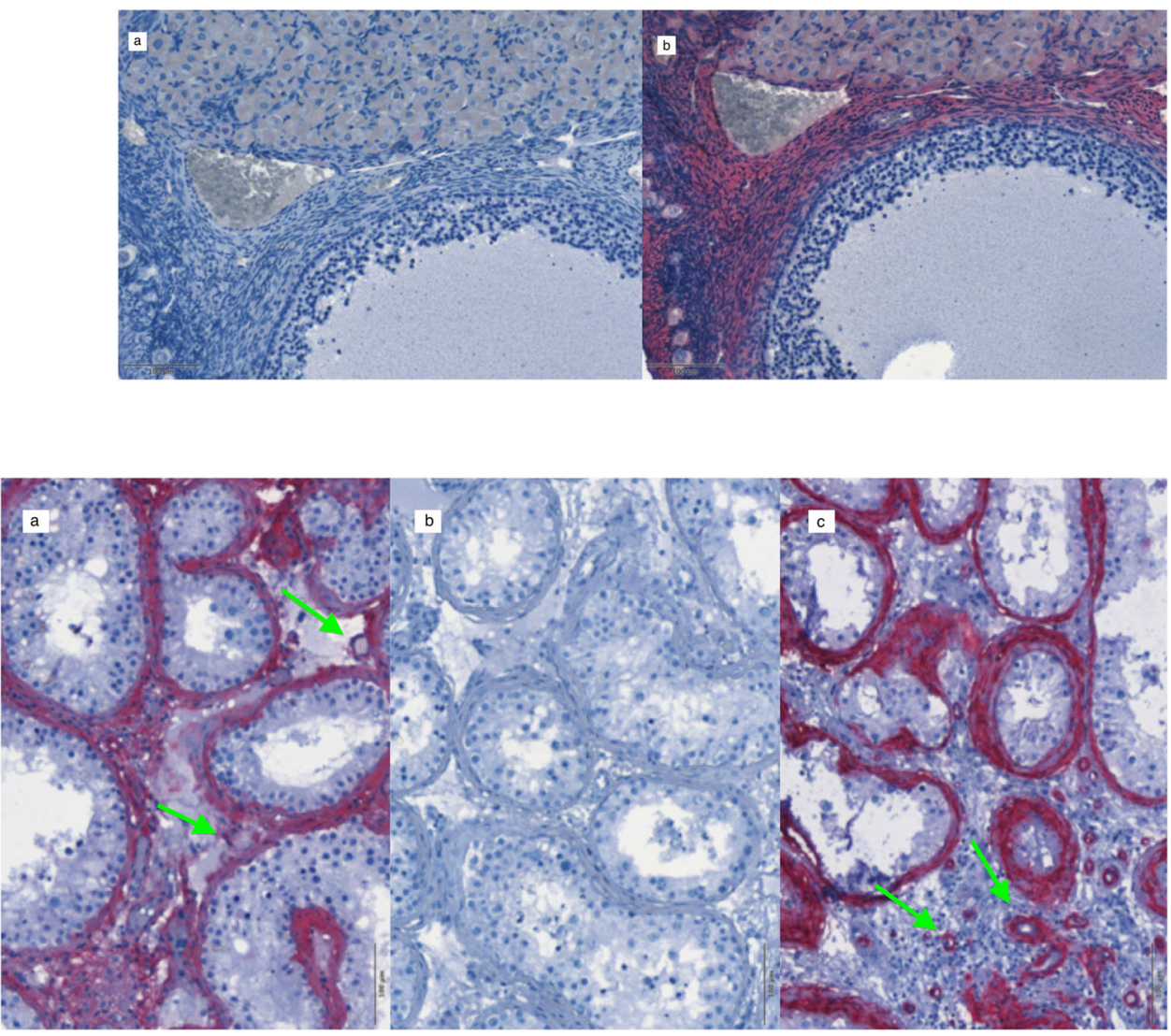

Fig. 2 Validation protocol for AMHR-2 IHC staining. Tissue sections from human testis; $\times 20$ magnification. a 1:500 AMHR-2 staining and hematoxylin counterstaining; b primary antibody omitted, using hematoxylin counterstaining only; c 1:500 $\alpha$-SMA staining and hematoxylin counterstaining. The green arrows point towards blood vessels

\section{Histological examination}

IHC images were acquired using a PreciPoint ${ }^{\circledast}$ M8 microscope (Precipoint, Freising, Germany) with $\times 20$ and $\times 60$ magnification and recorded using the ViewPoint ${ }^{\oplus}$ software.

\section{Results}

\section{Validation protocol}

Both in the human testicular and marmoset ovarian sections, AMHR-2 positive cells were identified in all titrations of the primary antibody with the same pattern of expression. In marmoset ovary (Fig. 1a, b), AMHR-2 positive cells were identified in the granulosa cell layer surrounding the oocyte; in human testis, mesenchymal peritubular cells resulted markedly stained by the primary antibody, with some resemblance to $\alpha$-SMA staining (Fig. 2a-c). As highlighted by the arrows in Fig. 2a, c, however, despite the similarities, blood vessels in testis samples are weakly labeled for AMHR-2 and strongly labeled for $\alpha$-SMA. 


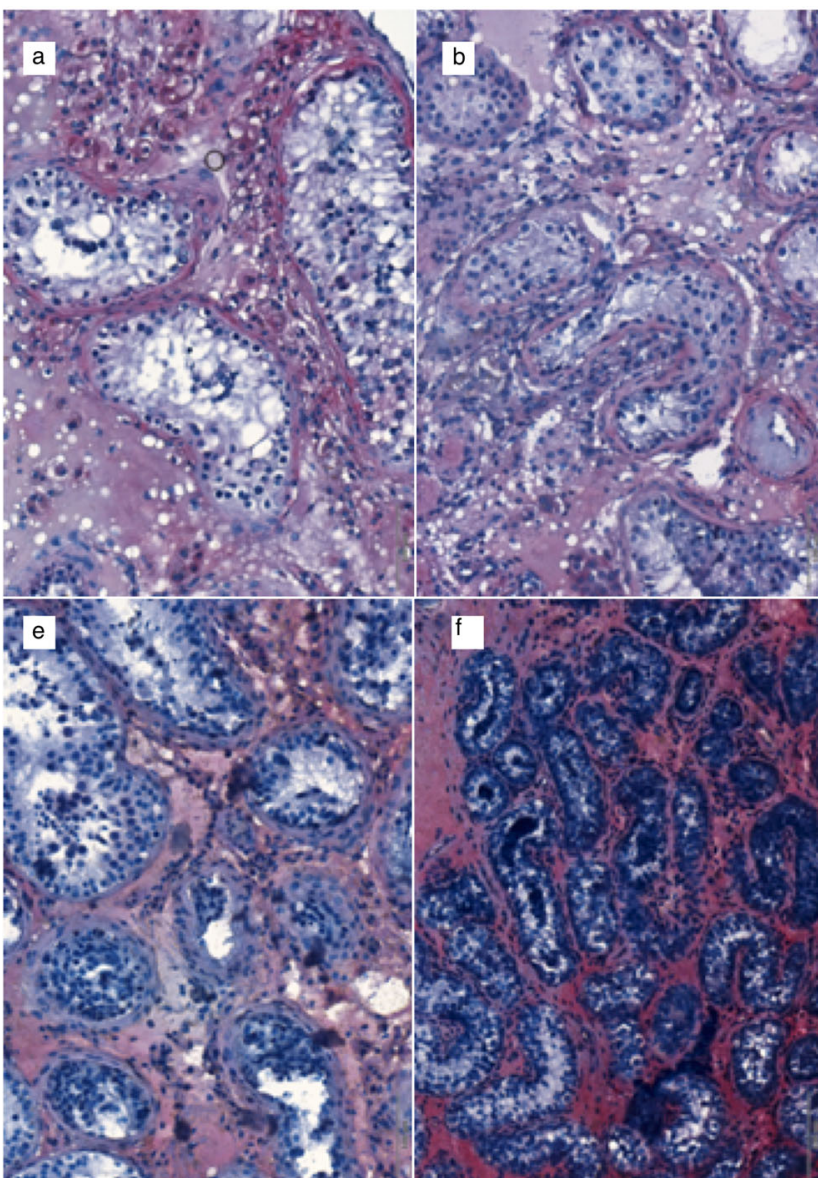

Fig. 3 Study protocol for AMHR-2 IHC staining. Tissue sections from human testis; $\times 20$ magnification; 1:500 AMHR-2 staining and hematoxylin counterstaining. a Spermatogenetic arrest. b Sertoli cell-only syndrome. c Mixed atrophy. d Klinefelter syndrome. e Hematological

\section{Study protocol}

Following the completion of our validation protocol, we performed the same IHC staining on testicular sections from seven patients with different testicular affections (Fig. $3 \mathrm{a}-\mathrm{g})$. The same patterns of expression for AMHR-2 were identified for SA (Fig. 3a), SCO (Fig. 3b), MA (Fig. 3c), and KS (Fig. 3d) patients: mesenchymal cells showed markedly positive staining in a thin layer surrounding tubular structures. As previously stated, IHC staining was also performed on two patients with hematological disease belonging to the AP project [23] undergoing cryopreservation of testicular tissue before full testicular maturation. In the tissue sections from a 14-year-old AP patient with non-Hodgkin lymphoma an adult-like pattern in AMHR-2 expression could be identified (Fig. 3e); contrarywise, in the tissue sections from a 5-year-old AP patient with Hodgkin lymphoma, intense, diffuse staining was observed (Fig. 3f) suggesting a change in the expression patterns of AMHR-2 during the transition through puberty.

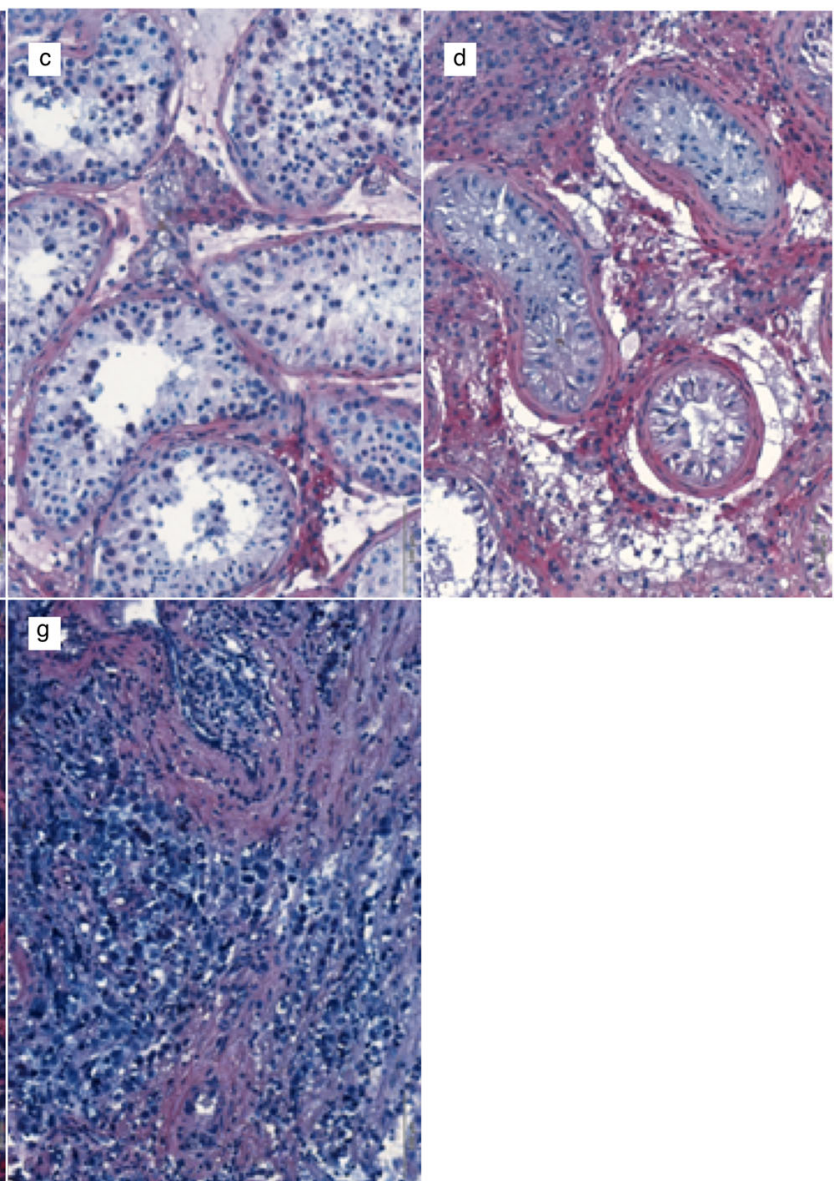

malignancy (non-Hodgkin lymphoma), 14 years old. f Hematological malignancy (Hodgkin lymphoma), 5 years old. g Nonseminomatous germ cell tumors

In tissue scans from the NSGCT patient, loss of testicular architecture was observed and AMHR-2 expression was therefore different from all remaining samples.

\section{Discussion}

This is the first study, to our knowledge, providing a detailed IHC characterization of AMHR-2 expression in healthy subjects as well as in a series of different testicular conditions. Our results suggest that expression of AMHR2 is decreased following the transition to adulthood in all tissue samples, mirroring reduced AMH concentrations: a progressively more diffused, intense staining was observed in prepubertal and pubertal tissue samples than in all other sections. Even in adults, however, AMHR-2 staining showed distinctive features: a thin layer of peritubular mesenchymal cells showed positive staining, suggesting a possible role for AMH even in adult testis. Despite almost nonmeasurable serum levels, intratubular 
concentrations of AMH are far greater [7, 24]. Several studies have reported a progressive decrease of AMH levels during aging [25-27], suggesting a progressive decline in Sertoli cell function, which is also fitting with current hypothesis on the negative effects of aging on the male reproductive system [28, 29]. As previously mentioned, several authors have investigated the possibility of AMH measurement as a prognostic tool for successful sperm retrieval with testicular sperm extraction techniques (TESE or microTESE): a meta-analysis study conducted by Toulis et al. [10] concluded that while the diagnostic value of AMH is not supported, the evidence in these regards is extremely limited. However, more recently, Alfano et al. [13] reported different results, with both $\mathrm{AMH}$ and AMH-to-testosterone ratio achieving with a predictive accuracy of 93 and $95 \%$ for sperm retrieval rate via microTESE. In patients with Klinefelter syndrome, no association was found between biomarkers of Sertoli cell function, including AMH, and microTESE success [30]; indeed, the pattern of AMH expression in Klinefelter patients is somehow different from normal, with a delay in the FSH-mediated decline occurring in puberty, possibly due to a temporary, functional compensation of Sertoli cells [31]. Still on the topic of different patterns of expression, Kistamás et al. have not found any statistically relevant correlation between AMHR-2 expression and age on the appendix testis [32] in a large series of patients undergoing surgical explorations for different conditions, such as hydrocele and varicocele; however, as the appendix testis is histologically different from testicular tissue [33], drawing an association with the present study is not feasible.

Little evidence has been found concerning the possible role of AMH in spermatogenesis [24]: a positive association between AMH concentrations (both in serum and in seminal plasma) and sperm quality has been reported in a small number of studies, although others have found no significant association. Peritubular cells are involved in passive motility of sperm cells: at the end of spermatogenesis spermatozoa are immotile, and sperm transit is allowed by rhythmic contractions of such peritubular cells. The similar patterns of expression for AMHR-2 and $\alpha$-SMA possibly suggest that in fact AMH in adult life could be involved in the regulation of sperm transit through tubules, partly supporting the positive association between sperm parameters and $\mathrm{AMH}$ concentrations in seminal plasma reported in some studies [24]. Expression of $\alpha$-SMA is induced by androgens and FSH [22], which at the same time act as triggers for downregulation of AMH secretion. The persistence of AMHR-2 in adult life might hint at a different physiologic role for AMH after the end of puberty: AMHR2 is no longer expressed by Sertoli cells, as expected following the end of the maturation process, but is still expressed by peritubular cells which support the passive movement of sperm. Several factors are involved in the regulation of peritubular cell contraction and relaxation [34]: this could perhaps provide an explanation to inconclusive evidence linking AMH levels to sperm parameters.

In our tissue sections, AMHR-2 expression is also preserved in testicular pathologies, such as Klinefelter syndrome and Sertoli cell-only syndrome; this is somewhat in contrast with previous reports suggesting that the tubular wall compartment is remodeled in men with impaired spermatogenesis [34].

\section{Conclusions}

Our IHC study showed that AMHR-2 is expressed in testicular tissue sections, both in humans and in animal models, in a thin layer of peritubular mesenchymal cells. Expression of AMHR-2 is conserved in healthy controls and in different testicular pathologies; patterns of expression are remarkably similar to $\alpha$-SMA. Expression of AMHR-2 is clearly different before the onset of puberty, closely mirroring serum AMH levels. However, while in adult males serum AMH is almost negligible, the significantly higher concentrations of this hormone in tubular fluid might be enough to elicit a response from the receptor on the peritubular wall, possibly resulting in changes in sperm parameters. However, given the little evidence suggesting a link between sperm parameters and AMH levels, our hypothesis requires further testing.

Acknowledgements We wish to thank all clinicians, biologists, and technicians working at the CeRA for their support in this research. A.S. and S.S. would also like to thank Itay Spector (Center for fertility preservation, Sheba Medical Centerc, Tel Hashomer, Israel) for his support in identifying the primary antibody to be used in this research. Open Access funding provided by Projekt DEAL.

Funding The study was supported by the CRU 326 (Schlatt funding) of the German Research Foundation.

Author contributions The study was co-conceived by A.S. and S.S. A.S. conceived the study, performed the IHC method, and wrote the early draft of the manuscript. A.M.I. and S.K. critically appraised and revised the paper. S.K. surgically retrieved the human tissue samples. S.S. retrieved tissue samples from monkeys, tutored A.S. for IHC, and provided critical appraisal and revision of the manuscript.

\section{Compliance with ethical standards}

Conflict of interest The authors declare that there is no conflict of interest that could be perceived as prejudicing the impartiality of the research reported.

Ethical approval All applicable international, national, and/or institutional guidelines for the care and use of animals were followed. All procedures performed in studies involving human participants were in 
accordance with the ethical standards of the institutional and/or national research committee and with the 1964 Helsinki declaration and its later amendments or comparable ethical standards.

Publisher's note Springer Nature remains neutral with regard to jurisdictional claims in published maps and institutional affiliations.

Open Access This article is distributed under the terms of the Creative Commons Attribution 4.0 International License (http://crea tivecommons.org/licenses/by/4.0/), which permits unrestricted use, distribution, and reproduction in any medium, provided you give appropriate credit to the original author(s) and the source, provide a link to the Creative Commons license, and indicate if changes were made.

\section{References}

1. R.L. Cate, R.J. Mattaliano, C. Hession, R. Tizard, N.M. Farber, A. Cheung, E.G. Ninfa, A.Z. Frey, D.J. Gash, E.P. Chow et al. Isolation of the bovine and human genes for Mullerian inhibiting substance and expression of the human gene in animal cells. Cell 45(5), 685-698 (1986). https://doi.org/10.1016/0092-8674(86)90783-x

2. H.E. Chemes, R.A. Rey, M. Nistal, J. Regadera, M. Musse, P. Gonzalez-Peramato, A. Serrano, Physiological androgen insensitivity of the fetal, neonatal, and early infantile testis is explained by the ontogeny of the androgen receptor expression in Sertoli cells. J. Clin. Endocrinol. Metab. 93(11), 4408-4412 (2008). https://doi.org/10.1210/jc.2008-0915

3. R.P. Grinspon, L. Andreone, P. Bedecarras, M.G. Ropelato, R.A. Rey, S.M. Campo, I. Bergada, Male central precocious puberty: serum profile of anti-mullerian hormone and inhibin B before, during, and after treatment with GnRH analogue. Int J. Endocrinol. 2013, 823064 (2013). https://doi.org/10.1155/2013/823064

4. F.E. Franke, K. Pauls, R. Rey, A. Marks, M. Bergmann, K. Steger, Differentiation markers of Sertoli cells and germ cells in fetal and early postnatal human testis. Anat. Embryol. 209(2), 169-177 (2004). https://doi.org/10.1007/s00429-004-0434-x

5. C. Pleuger, D. Fietz, K. Hartmann, W. Weidner, S. Kliesch, M.K. O'Bryan, A. Dorresteijn, M. Bergmann, Expression of katanin p80 in human spermatogenesis. Fertil. Steril. 106(7), 1683-1690 e1681 (2016). https://doi.org/10.1016/j.fertnstert.2016.08.043

6. K.P. Tremellen, M. Kolo, A. Gilmore, D.N. Lekamge, Antimullerian hormone as a marker of ovarian reserve. Aust. N. Z. J. Obstet. Gynaecol. 45(1), 20-24 (2005). https://doi.org/10.1111/j. 1479-828X.2005.00332.X

7. E. Matuszczak, A. Hermanowicz, M. Komarowska, W. Debek, Serum AMH in physiology and pathology of male gonads. Int J. Endocrinol. 2013, 128907 (2013). https://doi.org/10.1155/2013/ 128907

8. S. Allard, P. Adin, L. Gouedard, N. di Clemente, N. Josso, M.C. Orgebin-Crist, J.Y. Picard, F. Xavier, Molecular mechanisms of hormone-mediated Mullerian duct regression: involvement of beta-catenin. Development 127(15), 3349-3360 (2000)

9. N. Josso, R.A. Rey, J.Y. Picard, Anti-Mullerian hormone: a valuable addition to the toolbox of the pediatric endocrinologist. Int J. Endocrinol. 2013, 674105 (2013). https://doi.org/10.1155/ 2013/674105

10. K.A. Toulis, P.K. Iliadou, C.A. Venetis, C. Tsametis, B.C. Tarlatzis, I. Papadimas, D.G. Goulis, Inhibin B and anti-Mullerian hormone as markers of persistent spermatogenesis in men with non-obstructive azoospermia: a meta-analysis of diagnostic accuracy studies. Hum. Reprod. Update 16(6), 713-724 (2010). https://doi.org/10.1093/humupd/dmq024
11. V. Mitchell, F. Boitrelle, P. Pigny, G. Robin, C. Marchetti, F. Marcelli, J.M. Rigot, Seminal plasma levels of anti-Mullerian hormone and inhibin $\mathrm{B}$ are not predictive of testicular sperm retrieval in nonobstructive azoospermia: a study of 139 men. Fertil. Steril. 94(6), 2147-2150 (2010). https://doi.org/10.1016/j. fertnstert.2009.11.046

12. T. Mostafa, M.K. Amer, G. Abdel-Malak, T.A. Nsser, W. Zohdy, S. Ashour, D. El-Gayar, H.H. Awad, Seminal plasma antiMullerian hormone level correlates with semen parameters but does not predict success of testicular sperm extraction (TESE). Asian J. Androl. 9(2), 265-270 (2007). https://doi.org/10.1111/j. 1745-7262.2007.00252.x

13. M. Alfano, E. Ventimiglia, I. Locatelli, P. Capogrosso, W. Cazzaniga, F. Pederzoli, N. Frego, R. Matloob, A. Sacca, L. Pagliardini, P. Vigano, P. Zerbi, M. Nebuloni, M. Pontillo, F. Montorsi, A. Salonia, Anti-Mullerian hormone-to-testosterone ratio is predictive of positive sperm retrieval in men with idiopathic non-obstructive azoospermia. Sci. Rep. 7(1), 17638 (2017). https://doi.org/10.1038/s41598-017-17420-z

14. W.M. Baarends, M.J. van Helmond, M. Post, P.J. van der Schoot, J.W. Hoogerbrugge, J.P. de Winter, J.T. Uilenbroek, B. Karels, L. G. Wilming, J.H. Meijers et al. A novel member of the transmembrane serine/threonine kinase receptor family is specifically expressed in the gonads and in mesenchymal cells adjacent to the mullerian duct. Development 120(1), 189-197 (1994)

15. N. Josso, N. Clemente, Transduction pathway of anti-Mullerian hormone, a sex-specific member of the TGF-beta family. Trends Endocrinol. Metab. 14(2), 91-97 (2003)

16. C. Belville, S.P. Jamin, J.Y. Picard, N. Josso, N. di Clemente, Role of type I receptors for anti-Mullerian hormone in the SMAT1 Sertoli cell line. Oncogene 24(31), 4984-4992 (2005). https:// doi.org/10.1038/sj.onc. 1208686

17. F. Tuttelmann, N. Dykstra, A.P. Themmen, J.A. Visser, E. Nieschlag, M. Simoni, Anti-Mullerian hormone in men with normal and reduced sperm concentration and men with maldescended testes. Fertil. Steril. 91(5), 1812-1819 (2009). https:// doi.org/10.1016/j.fertnstert.2008.02.118

18. R.V. Trigo, I. Bergada, R. Rey, M.G. Ballerini, P. Bedecarras, C. Bergada, S. Gottlieb, S. Campo, Altered serum profile of inhibin $\mathrm{B}$, Pro-alphaC and anti-Mullerian hormone in prepubertal and pubertal boys with varicocele. Clin. Endocrinol. 60(6), 758-764 (2004). https://doi.org/10.1111/j.1365-2265.2004.02051.x

19. D. Goulis, G. Mintziori, N. Koliakos, D. Hatzichristou, I. Papadimas, K. Hatzimouratidis, D.G. Goulis, Inhibin B and antiMullerian hormone in spermatic vein of subfertile men with varicocele. Reprod. Sci. 18(6), 551-555 (2011). https://doi.org/10. 1177/1933719110393024

20. R.A. Condorelli, R. Cannarella, A.E. Calogero, S. La Vignera, Evaluation of testicular function in prepubertal children. Endocrine 62(2), 274-280 (2018). https://doi.org/10.1007/s12020-018$1670-9$

21. M. Bergmann, S. Kliesch, Testicular biopsy and histology. in E. Nieschlag et al. (eds), Andrology (Springer-Verlag Berlin Heidelberg, 2010), p. 155-167. https://doi.org/10.1007/978-3540-78355-8_11

22. S. Schlatt, G.F. Weinbauer, M. Arslan, E. Nieschlag, Appearance of alpha-smooth muscle actin in peritubular cells of monkey testes is induced by androgens, modulated by follicle-stimulating hormone, and maintained after hormonal withdrawal. J. Androl. 14 (5), 340-350 (1993)

23. S. Kliesch, Androprotect and prospects for fertility treatment. Urol. A 55(7), 898-903 (2016). https://doi.org/10.1007/s00120-016-0161-y

24. J.M. Andersen, H. Herning, O. Witczak, T.B. Haugen, AntiMullerian hormone in seminal plasma and serum: association with sperm count and sperm motility. Hum. Reprod. 31(8), 1662-1667 (2016). https://doi.org/10.1093/humrep/dew121 
25. L. Aksglaede, K. Sorensen, M. Boas, A. Mouritsen, C.P. Hagen, R.B. Jensen, J.H. Petersen, A. Linneberg, A.M. Andersson, K.M. Main, N.E. Skakkebaek, A. Juul, Changes in anti-Mullerian hormone (AMH) throughout the life span: a population-based study of 1027 healthy males from birth (cord blood) to the age of 69 years. J. Clin. Endocrinol. Metab. 95(12), 5357-5364 (2010). https://doi.org/10.1210/jc.2010-1207

26. Y.H. Chong, N.A. Dennis, M.J. Connolly, R. Teh, G.T. Jones, A.M. van Rij, S. Farrand, A.J. Campbell, I.S. McLennan, Elderly men have low levels of anti-Mullerian hormone and inhibin $\mathrm{B}$, but with high interpersonal variation: a cross-sectional study of the sertoli cell hormones in 615 community-dwelling men. PLoS ONE 8(8), e70967 (2013). https://doi.org/10.1371/journal.pone.0070967

27. F. Ramezani Tehrani, M.A. Mansournia, M. Solaymani-Dodaran, S. Minooee, F. Azizi, Serum variations of anti-mullerian hormone and total testosterone with aging in healthy adult Iranian men: a population-based study. PLoS ONE 12(7), e0179634 (2017). https://doi.org/10.1371/journal.pone.0179634

28. S. Gunes, G.N. Hekim, M.A. Arslan, R. Asci, Effects of aging on the male reproductive system. J. Assist Reprod. Genet. 33(4), 441-454 (2016). https://doi.org/10.1007/s10815-016-0663-y

29. A. Sansone, S. Kliesch, A.M. Isidori, S. Schlatt, AMH and INSL3 in testicular and extragonadal pathophysiology: what do we know?
Andrology 7(2), 131-138 (2019). https://doi.org/10.1111/andr. 12597

30. J. Rohayem, R. Fricke, K. Czeloth, C. Mallidis, J. Wistuba, C. Krallmann, M. Zitzmann, S. Kliesch, Age and markers of Leydig cell function, but not of Sertoli cell function predict the success of sperm retrieval in adolescents and adults with Klinefelter's syndrome. Andrology 3(5), 868-875 (2015). https://doi.org/10.1111/andr.12067

31. R. Li, H.-Y. Xu, H.-X. Zhang, Z. Xiao, J. Qiao, Regulation of anti-Müllerian hormone (AMH) in males and the associations of serum AMH with the disorders of male fertility. Asian J. Androl. 21(2) (2019). https://doi.org/10.4103/aja.aja_83_18

32. K. Kistamas, O. Ruzsnavszky, A. Telek, L. Kosztka, I. Kovacs, B. Dienes, L. Csernoch, T. Jozsa, Expression of anti-Mullerian hormone receptor on the appendix testis in connection with urological disorders. Asian J. Androl. 15(3), 400-403 (2013). https://doi.org/ 10.1038/aja.2012.135

33. E. Rakha, F. Puls, I. Saidul, P. Furness, Torsion of the testicular appendix: importance of associated acute inflammation. J. Clin. Pathol. 59(8), 831-834 (2006). https://doi.org/10.1136/jcp.2005. 034603

34. A. Mayerhofer, Human testicular peritubular cells: more than meets the eye. Reproduction 145(5), R107-R116 (2013). https:// doi.org/10.1530/REP-12-0497 